Voix et Images

voixetimages

\title{
Seize distances pour le doigt, l'ouvert, la page
}

\section{Michel van Schendel}

Volume 11, numéro 2 (32), hiver 1986

Michel van Schendel

URI : https://id.erudit.org/iderudit/200551ar

DOI : https://doi.org/10.7202/200551ar

Aller au sommaire du numéro

\section{Éditeur(s)}

Université du Québec à Montréal

\section{ISSN}

0318-9201 (imprimé)

1705-933X (numérique)

Découvrir la revue

\section{Citer ce document}

van Schendel, M. (1986). Seize distances pour le doigt, l'ouvert, la page. Voix et Images, 11(2), 161-164. https://doi.org/10.7202/200551ar d'utilisation que vous pouvez consulter en ligne.

https://apropos.erudit.org/fr/usagers/politique-dutilisation/ 
Seize distances pour le doigt, l'ouvert, la page* Michel van Schendel

1. (1) Domaine de serpents, de bruissements, de sentiers, D'accents sur l'improbable doux.

(2) L'étamine pose l'araignée du vent Sur la page alors mobilisée de soie,

( 3$)$ Terreuse la sueur.

2. (4) L'aride emmêle un basalt et la main:

La terre, toute, est tendre d'une dent.

(5) Une fleur achève de déposer la nuit, Un mort. Il approuvait l'oiseau sur la coquille de noix.

( 6) Ce livre ouvert à la venue des vipères, Qui n'en craint l'oeil au levant?

Le livre alors a le mouvement froid d'une offrande.

3. ( 7) Je ne sais comment le dire, n'avoir aimé que toi.

Toute fleur appariée est une offense au respirant.

Je t'aime, toi. J'aime. Toi. Respiré je suis, toi respiration, odeur de toi.

( 8) J'aime, hérisse, suis aimé. Le dire comment par le haut du sentier

Qui prolonge l'ouvert de la demeure où je le mange,

Hérisson doux du ventre et du figuier.

L'amour là, en dessus, comme une vitre, et

l'épaisseur.

* À paraître à l'automne 1986 aux Éditions de l'Hexagone, dans

Cheminure (Extrême / livre des voyages). 
( 9) En dessous. Mangé je suis. Elle y a l'aile, et l'aile moi.

Le vert est dans le bleu l'identique des yeux, Et la distance de l'iris.

4. (10) Nous venons au hérisson, nous lui faisons la laine.

Comment peut-il, s'il est tout seul, comment peut-il aimer la laine?

5. (11) Nous allons par épis, nous allons au vent, nous prenons le buis.

Est-il amour que d'une ronce au mont d'un mur détruit?

(12) À l'accent du dos pour le moindre ouvert du doigt,

L'amie, la paume, une ombre, une eau qui boit.

6. (13) Le livre alors, rosier de pages,

Main de tant d'ongles, de dents sur le blanc d'une pierre.

(14) La fable nous épelle d'y faire une mémoire, Nous construisons le temps à bêche pour le dire.

(15) À quatre bras, travail, amour, amandier de peau,

Oui, pour tout l'écarquillé, oui pour l'advenue.

7. (16) Une balancelle, un bout de fil aux succulences latérales,

Trois courbes aiguilles de bec font le geste d'une odeur.

(17) Démontrez-moi l'extrémité. Au bout du champ, la coloquinthe.

8. (18) Cet autre-là tout autre, là. Nous en faisons lecture, dilection.

Nous apprenons le coloris des autres par abondance de lettres. 
(19) Réponse aux marches de pierre une table, Le matin tu t'assieds, l'oeil bleu

Fait éloge au temps, tu fais duvet de l'ongle même.

9. (20) Alors oui, dans le grand débraillant de l'herbe, À cascade, et petits, les deux pas de comptine:

Ici dit-on dirandes, brande, amarande, comptes ronds

À l'envol, à pied franc, sang de ciel tu le changes.

(21) Une enfance, on l'accueille, on fait l'intelligence,

On traverse les murs, d'ombre et blancs, muguets. Un nuage en crapaud, bras en corbeille et tout l'enfant

Ramasse la pluie dans sa tasse d'étain.

10. (22) Le plafond m'ordonne le refent d'où je le traverse

Et ne le romps pourtant, l'aimant trop de tant de poutres.

Mais quand même au ciel audible un petit doigt l'entrouvre.

(23) Quelque ombre, une ombre,

11. (24) Une agacée, réplique au bec, un lancement de tasse

Aux implacides, pars, on se voit d'une épaule, on esquisse le pas.

(25) La gueule ouverte, non toi, moi non plus le poing;

Nous frôlions cette mousse qui meurt par violence de l'œil.

(26) Et d'un silence, dans le tracé possible du cruel au plus accompli,

Oui par l'égaré, d'une aiguille non pas, mais le tendre des bras. 
12. (27) Alors ce livre, on fait semblant l'écrire

D'un oeillet qui tremble au bord de table où la main froisse le feuillet.

(28) Oui, l'ancienne et toute douce, vive,

Apprentissage d'y penser, pierre de tombeau qui fait l'école au doigt,

(29) Et c'est géométrie.

13. (30) Quand la neige ailleurs, ici le froid des os, fait mortier d'amour, Il n'est tissé qu'à dentellière,

Au traversier du ventre, au portant des yeux,

(31) Verts, bleus, foncés de soleil et comme gouttière aux pluies,

Elles n'ont froid qu'à prime vent sur des noeuds de bois,

Aime-moi, tu m'aimes d'une orange, alors je t'aime aux dents.

14. (32) Tissage, lettre à notre laine,

(33) Tu enlèves le soulier, tu dis «mets le pied sur le pied», tu dis «sur l'étrier du pied», tu dis «à piétrier », tu me dis «emmène-moi », tu m'emmènes, je t'ébranche.

15. (34) Mains en coque de luth au silence d'entreciel, Ces lieux font lèvre sur l'amour, le nôtre, plus ancien que de nous.

(35) Nous prenons le mont de l'herbe, le cri du linge bat le vent,

16. (36) Alors ce livre, autre à l'autre, bague de puits, ou peut-être aux clenches de fenêtre, orient: 